\title{
From Stressed Self-Esteem to Emotional Climate Change
}

\author{
Georg Franck* \\ Institute for Architectural Sciences, Vienna, Austria
}

\author{
*Corresponding author: Georg Franck, Institute for Architectural Sciences, E259 01 \\ Digital Architecture and Spatial Planning, Vienna University of Technology, Vienna, \\ Austria.
}

Received Date: December 17, 2019

Published Date: January 14, 2020

\begin{abstract}
In a world of global interdependence, in addition to the well-known climate change, another form of pollution threatens coexistence on the planet: an increasing heating of the emotional climate and concomitant corruption of cooperative behaviour. Waves of hostility, incitement and disinformation circulate around the world, massive threats and baseless allegations spread virally. They threaten our coexistence on the planet no less than the careless handling of natural resources. We risk a dangerous erosion of the social context. In addition to the ecology of material natural resources, we urgently need an ecology of emotion. The parallels and connections between physical global warming and mental climate warming are astonishing, and it is astounding that they have been ignored for so long (see Dorothea Franck, Emotional Climate Heater, online https: // dorotheafranck.word press.com/a-plea-for-awareness-watch-your-emotional-footprint /).
\end{abstract}

\section{The Fight for The Victim Role}

Globally networked communication connects everyone and everything. At the same time, prosperity gaps and global shifts in labour markets are causing an unprecedented rise in global migration. The complexity, confusion and speed of globalization overburdens our emotional even more than our rational competence. The extent to which anxiety and diffuse indignation can be exploited for obscure purposes is shown by the political shifts of recent years.

Crucial to understanding these shifts is the question of whether they have a common denominator. The answer is a resounding 'yes'. In the foreground is the ubiquitous fight for the victim role. The diffuse fears and confused defensive postures come together in a shared sense of being overlooked and abandoned. They manifest themselves not only in the struggle for the material benefits of globalization, but also in the struggle for media attention. The lack of social recognition is so hurtful because it strikes at the heart of the person: the way in which a person conceives of their-self: their self esteem.

But if withdrawal symptoms from lack of social recognition are behind the rampant willingness to be incited to anger, one should reconsider those accusations of irrationality and regressiveness on the part of the agitated masses. Instead, we should take the opportunity of venturing a meaningful and understanding interpretation--one which may also open up new perspectives of resistance.

\section{Social Recognition and The Economy of Self-Worth}

Self-esteem is the affective side of self-awareness. And it has its own logic. In contrast to the cognitive side of self-awareness, affective self-awareness must not claim autonomy. It eminently depends on outer esteem. It has become perfectly obvious that the ego one can afford depends on its income of appreciative attention. Affective self-awareness' own logic is that of the psychic economy, which converts the flow of attention received into the asset of selfworth.

Decreasing incomes put pressure on this economy, as do rising demands. In the case that the economy collapses under stress and becomes unpredictable, our original diagnosis is correct, certifying the sheer irrationality and regressiveness suffered as withdrawal symptoms. And yet, our self-esteem is resilient, and shows itself equipped to weather the storm. How, then, does the economy of self-worth withstand such stress?

The conversion of attention income into self-esteem proves itself truly an economy of sorts with its inclination to resort to 
tricks of 'creative accounting' under stress. Since the stress in the case of affective self-awareness can originate both from the income side and from one's own claim of self-esteem, different forms of 'cooking the books' should be observed.

In fact, fraudulent accounting of self-worth knows two common tricks. One is called vanity, the other resentment. Vanity comes into play when the inner claim overdraws the outer means. The trick, then, is to double standards in evaluating income depending on whether it comes from flattering or critical quarters. If you adapt the appreciation opportunistically, the flatterers' attention rises in book value. One can, therefore, butter up one's balance by choosing one's friends according to their preparedness to dole out adulation.

We all know the corruption wrought by flattering praise; but equally we all have made acquaintance with the terrible distress brought about when the attention we believe we cannot do without is denied. We no longer know what else to do than to resort to an act of self-help: we try to persuade ourselves and others that those who deny us the longed-for attention are themselves unworthy of respect. We make unreserved use of the trick that vanity resorts to only furtively. In taking this recourse we feel ourselves unquestionably to be victims, and give ourselves thereby the license to unrestrained bullying.

Is not the insurrection of the insulted masses something of a mobilization of such self-defence? Is it not a mass release of resentment that is behind the emotional climate change? For those who feel pressed to denigrate others in order to save his or her own self-esteem, truth is of secondary concern. Now that reasons, however flimsy, for resentment are established, the 'victim' now has a quite another problem--namely that of a new attention dependency. Resentment is in need of resonance. If the denunciation is to be effective, it must be absorbed by others who are seeking confirmation of their own grievances, and who will in turn pass it on further.

The mass release of resentment may therefore be said to have two main drivers. First, significant parts of the population must have become acquainted with the distress of keeping self-esteem intact in the context of their income of attention. Secondly, and equally vitally, the rapid dissemination of resentment must be possible. With the advent of social media in an increasingly politically and economically volatile world, both these conditions now apply in those societies that most violently encounter this emotional climate change. To look at it another way, it is no surprise that inherent in the most technically advanced societies, which profit most from globalization, is a huge gulf between the winners and losers.

The concerns of those worried about job losses and labour migration have a hard time getting into the leading media of public opinion. It is not only the case that the articulation of their reservations might fail to make it through the filter of political correctness--but that their ability to reach out to a wider audience has also remained systematically curbed as long as the mainstream has been controlled by the paternalism of dedicated journalism. It belonged to the professional honour of the classical journalist to serve the audience with objectivity and reflection instead of merely aiming to please the crowd. For a long time now the medium of classic journalism has been under existential pressure, having now to compete with the rapid rise of new media. New media can be defined as those media that have left the sale of information for money behind to focus on the attraction of attention to be sold as a service to the advertising industry. Under the pressure of producing attraction services in the first place, a shift of power between journalism, public relations and advertising has taken place, associated with a sustained loss of trust in journalism (as sharply analysed by Fengler, Susanne \& Stephan Ruß-Mohl, Journalists and the information-attention markets: Towards an economic theory of journalism, in: Journalism, 2008 - journals.sagepub.com). Where the service of attraction becomes more important than the production of news and reflected opinion, the vox populi consequently gets new chances to assail the bastion of journalistic virtue.

A real breach of the dam occurred with the arrival of social media. The business idea of Facebook, Twitter \& Co is to scale the business model of ad-financed mass media down to the vendor's tray. They make it possible to publish anything and everything online with nothing more than a smartphone at hand, and to profiteer by exploiting the attraction performance measured by the medium. Anyone who can publish on the World Wide Web is able to participate in the global battle for attention with measured results. Anyone can become a star by uploading a video on Youtube or serving up a misleading story on Facebook to fit a particular vulgar narrative. It suffices that the number and rate of increase of the clicks is noticed; the content is secondary. The new media succeed less in providing significant content than in exploiting our tendency to pay attention to what others pay attention to. In this way success in attracting attention becomes self-perpetuating.

This tendency of self-reinforced conspicuousness is particularly conducive to that resentment which seeks validation. By itself, this search is charged with potential synergy since it is only in its resonance that resentment is in its element. Where the willingness to revolt is common, it requires just a spark of confirmation to release avalanches of aggressive insults, hatred and suspicion, which, once released, sweep through the new media and engulf the already-weakened edifice of old media. The uproar consuming social media and the widespread sharing of negative emotions have blossomed into real recipes for success in the battle for likes and followers.

So, what it falls to us to explore is not only the alignment of rampant frustration and media resonance, but how the use of resentment has come to be the dominant strategy of overweening narcissists. The facilitation of popular outrage and a promise of revenge on the arrogant elites seems to be the very best way to capture the masses of attention with which the greedy ego enriches itself. Thus, even as part of these elites and in unsurpassed 
arrogance, one can rise to be the leader of the storm on the bastions of these same elites--and this only for the purpose of setting the crown on one's own vanity.

\section{Acknowledgement}

None.

\section{Conflict of interest}

Author declare no conflict of interest. 